\title{
Buena Administración y procedimiento administrativo en el Ecuador
}

Good Administration and Administrative Procedure in Ecuador

\author{
Sheyla Cuenca Flores* \\ Investigadora Jurídica Lex Conseil Abogados \\ Información del Artículo \\ Original - Ruptura, 2020 \\ Artículo recibido/ Received: 28 de junio, 2020 \\ Artículo aceptado/Accepted: 8 de julio, 2020
}

\section{Citación}

Cuenca, S. (2020). Buena administración y procedimiento administrativo en el Ecuador. Revista Ruptura Asociación Escuela de Derecho PUCE, p (283-301).

DOI: $10.26807 /$ rr.vi02.56

Resumen: La buena administración hace referencia a aquella institucionalidad que cumple las disposiciones establecidas en el ordenamiento normativo, justifica sus decisiones y se orienta a la consecución del interés público y protección de derechos de las personas. Como derecho, principio u obligación ha sido incorporada de forma paulatina a los diferentes ordenamientos jurídicos. En el Ecuador, únicamente el Código Orgánico Administrativo tiene una norma que reconoce este derecho, sin otorgarle contenido. Es preciso articular

* Abogada, por la Pontificia Universidad Católica del Ecuador. Licenciada en Ciencias Jurídicas, por la Pontificia Universidad Católica del Ecuador. Especialista en Derecho Administrativo, por la Universidad Andina Simón Bolívar. Magister en Derecho Administrativo, por la Universidad Andina Simón Bolívar. Doctorando en Derecho, por la Universidad Carlos III de Madrid. Partner en el estudio jurídico Lex Conseil, Quito, Ecuador. Correo electrónico: sheylacuencaflores@gmail.com 
medidas que garanticen el efectivo cumplimiento de este derecho en el procedimiento administrativo.

Palabras Clave: Buena administración, administración pública, derecho administrativo, procedimiento administrativo.

\begin{abstract}
Good administration refers to the institution that complies with the provisions established in the normative order, justifies decisions and is oriented to the achievement of the public interest and protection of people's rights. As a right, principle or obligation, it has been gradually incorporated into the different legal systems. In Ecuador, only the Organic Administrative Code recognizes this right, without granting it with content. It is necessary to articulate measures to guarantee the right to good administration in the administrative procedure.
\end{abstract}

Keywords: Good administration, public administration, administrative law, administrative procedure.

\title{
Introducción
}

El Estado como estructura, desde sus inicios y a consecuencia de su evolución, se orientó a la consecución de fines determinados. Estos fueron modificándose o perfeccionándose según el modelo de Estado. En la actualidad, gran parte de los países orientan su actuar a la consecución de un objetivo base, la satisfacción del bien común, del interés público y protección de derechos de las personas.

Con el objeto de satisfacer de forma efectiva su finalidad principal, el poder del Estado se articula en funciones que ejecutan determinadas actividades a través de órganos e instituciones. Cada una de ellas; y, desde luego el ordenamiento que los regula propende a la satisfacción de los fines descritos.

La Administración Pública y el Derecho Administrativo, son parte de la institucionalidad del Estado; y, como ocurrió con este, la Administración y Derecho Administrativo, son producto de una evolución histórica compleja (Damsky, 2019). 
No podríamos hablar de Administración Pública, sin un Derecho Administrativo. La primera goza de atributos de unilateralidad, autoritarismo y otros, frente a los cuales es imperativa la existencia de un ordenamiento que efectúe control, encauce su finalidad a la fijada por el Estado y rectifique las eventuales desviaciones (Parejo Alfonso, 2012). Comadira y Escola (s.f.) al referirse al Derecho Administrativo y a la Administración Pública, hablan de la exorbitancia como su característica. Advierte que esta rama, es una rama esencialmente política, por lo que debe observarse un especial equilibrio.1 Para tal equilibrio, se requiere la articulación de un ordenamiento jurídico.

\section{La Administración Pública}

La evolución histórica a la que hacemos referencia y las finalidades a las que se orienta la norma que regula la Administración Pública, permiten concebir al Derecho Administrativo como un derecho Constitucional concretizado, pues la Administración Pública se ha convertido en el instrumento para la ejecución del programa Estatal (Parejo Alfonso, 2012).

Siendo el Derecho Administrativo, un derecho constitucional concretizado, no resulta extraño afirmar que los fines que orientan la actividad estatal; $y$, que han sido insertos en el texto de la Constitución,

1 Entre las primeras: creación unilateral y presunción de legitimidad de sus actos, ejecutoriedad de éstos, potestad de volver sobre ellos por razones de ilegitimidad o inoportunidad llamadas sustanciales; y, procesales plazos breves de caducidad para accionar judicialmente contra el Estado, mayor plazo para el cumplimiento de ciertas cargas procesales, entre otras. Sobre las garantías hace mención a las sustanciales, el principio de juridicidad; la propiedad; la igualdad; la razonabilidad del actuar administrativo; el acceso a la Justicia; responsabilidad del Estado y de sus funcionarios. Mientras que las procesales son: el informalismo en favor del administrado (o, más propiamente, formalismo moderado a causa del carácter de colaborador que a éste corresponde reconocerle), un concepto amplio de legitimación y el debido procedimiento previo a todo acto administrativo, que incluye el debido proceso adjetivo. (Comadira y Escola, s.f.) 
son los mismos que deben conducir la actuación de la Administración Pública. Pues como lo señalan Comadira y Escola (s.f.), toda la actuación del Estado, encuentra su fundamento jurídico primario y límite en la Constitución del Estado, así como en su sistema de juridicidad.

Así lo resalta el profesor Rodríguez-Arana (2015), quien concibe al Derecho Administrativo como la rama del Derecho Público, que se orienta a la realización del modelo de Estado Social y democrático del Derecho. Dependiente del interés general y de aquellos asuntos que reclaman ser satisfechos en el marco de la racionalidad y justicia. El profesor enfatiza, que en modelos democráticos avanzados, las personas dejan de ser sujetos pasivos o inertes que se limitan a recibir bienes o servicios, para convertirse en sujetos activos y partícipes en la toma de decisiones de la Administración Pública, orientadas a un efectivo desarrollo en libertad solidaria (Rodríguez-Arana, 2014).

En este contexto, toma relevancia el concepto de Buena Administración, entendida como:

Aquella que cumple con las funciones que le son propias en democracia. Es decir, una Administración Pública que sirve objetivamente a la ciudadanía, que realiza su trabajo con racionalidad, justificando sus actuaciones y que se orienta continuamente al interés general. (Rodríguez-Arana, 2014, 26)

Tomó aún más vigencia este concepto en el período de tiempo en el cual, el llamado Estado de Bienestar se volvió estático; y, la Administración, lejos de cumplir sus funciones y orientarlas a la satisfacción del interés general, se vio ensombrecida por prácticas erróneas y alejadas de las disposiciones jurídicas (Rodríguez-Arana, 2014).

Si bien no es un concepto nuevo, lo sigue siendo hoy en países como el nuestro. Como derecho del ciudadano y principio rector de las actuaciones de la Administración Pública. En un primer momento, el reconocimiento del derecho fundamental a la buena administración se verifica en la Recomendación número R (80) 2 del Comité de Ministros del Consejo de Europa el 11 de marzo de 1980, en lo relativo al ejercicio de poderes discrecionales por parte de las autoridades admi- 
nistrativas. Posteriormente, en la jurisprudencia del Tribunal de Justicia de las Comunidades Europeas y del Tribunal de Primera Instancia. Además, en la Carta Europea de los Derechos Fundamentales de diciembre de 2000 y se ratifica tal reconocimiento en la Carta expedida de 12 de diciembre de 2007 y 2016. (Rodríguez-Arana, 2014).

Este derecho fundamental, ha ido operando de forma progresiva en diferentes ordenamientos jurídicos. Como se dijo, es producto de la redefinición de fines Estatales y la consideración de la persona como eje central del actuar estatal. Así lo resalta Rodríguez-Arana, al señalar que es frecuente que las nuevas Constituciones incorporen en su texto este derecho "Por una poderosa razón: porque la razón de ser del Estado y de la Administración es la persona, la protección y promoción de la dignidad humana y de todos sus derechos fundamentales" (Rodríguez-Arana, 2014, 25).

Son parte del Derecho a la Buena Administración ${ }^{2}$ entre otros, el derecho a la motivación de las actuaciones administrativas, dado que, toda decisión de la Administración deberá fundarse en razonamientos adecuados. En palabras del profesor Rodríguez-Arana, mientras más extensa e intensa sea la discrecionalidad, más intensa y extensa deberá ser la motivación. El derecho a la tutela administrativa efectiva, durante la sustanciación del procedimiento administrativo, ordena a la Administración que su actuar evite que el ciudadano se encuentre en situación de indefensión. El derecho a obtener una resolución en un plazo razonable, se fundamenta en que la Administración deberá emitir un pronunciamiento en plazos que permitan al ciudadano hacer efectivo su derecho a la defensa, con uso de medios materiales y personales que se encuentren a disposición de la Administración (Rodríguez-Arana, 2014).

Se le ha atribuido además "el carácter de principio orientador del procedimiento administrativo que tiene por finalidad proteger las

2 El artículo 41 de la Carta de los Derechos Fundamentales de la Unión Europea, regula el derecho a la buena administración. "ARTÍCULO 41.- Derecho a una buena administración. 
garantías jurídicas de cualquier persona ante las decisiones de la Administración" (Milkes, 2018, 158). Entre otros, estos principios son: juridicidad, servicio objetivo a los ciudadanos, principio promocional de los poderes públicos, racionalidad, igualdad de trato, eficacia, publicidad de las normas, seguridad jurídica, previsibilidad y certeza normativa, proporcionalidad, ejercicio normativo del poder, imparcialidad e independencia, relevancia, coherencia, buena fe, confianza legítima, asesoramiento, responsabilidad, facilitación, celeridad, transparencia y acceso a la información de interés general, protección de la intimidad, ética, debido proceso, cooperación (Rodríguez-Arana, 2014).

La buena administración, es entonces, el resultado palpable de un largo proceso de evolución de distintas instituciones, dentro de las que se incluye el Estado. Cuyos fines en la actualidad se orientan a la consecución efectiva del interés público y protección efectiva de los derechos de los ciudadanos. La evolución debe articular su regulación e instituciones a la satisfacción de necesidades del individuo y contribuir a su desarrollo integral en observancia de los derechos del ciudadano como fin último. En otras palabras, "se trata de un útil instrumento en el control administrativo en garantía de los derechos e intereses de los ciudadanos, tanto individuales como colectivos" (Ponce, 2014, 36).

El estatus especial de la buena administración, como derecho, principio u obligación, constituye una también especial exigencia para la Administración Pública., pues no cabría alegar ausencia de regulación o insuficiencia de recursos para no garantizar este derecho. La Administración está llamada a desarrollar las políticas, implementar herramientas y adecuar su normativa, con el objeto de garantizar a satisfacción el ejercicio del derecho. Recordemos que los principios que rigen un modelo de Estado, no sólo constan en su Carta Suprema, sino que se transfieren y forman parte de cada una de sus instituciones y órganos, guían su actuar y dictan un modelo de conducta orientado a la consecución de un fin. 


\section{Regulación de la Buena Administración en Ecuador}

La Constitución de la República del 2008 define al Estado como un Estado constitucional, de derechos y justicia. Así lo establece el artículo 1 del texto: "Art. 1.- El Ecuador es un Estado constitucional de derechos y justicia, social, democrático, soberano, independiente, unitario, intercultural, plurinacional y laico. Se organiza en forma de república y se gobierna de manera descentralizada." (CRE, 2008, art. 1). En el Estado Constitucional, la Constitución adquiere especial importancia, pues determina el contenido de la ley, estructura del poder, reconoce derechos que se conciben como límites y vínculos del poder. Los poderes del Estado están llamados a efectivizar y procurar la maximización de los derechos de las personas. Sobre el calificativo "derechos", particular término que se incluyó en el texto constitucional, se refiere a la obligación de todo poder sea este privado o público, incluido el constituyente, de someterse a los derechos (Ávila, 2009).

El texto constitucional del año 2008, de conformidad su estructura, principios y derechos insertos, coloca a la persona como eje central del actuar estatal. De esta forma, toda la institucionalidad del Estado está llamada a adecuar su actuación a la efectiva garantía de derechos. Siendo la persona y sus derechos, como se ha dicho, el eje del actuar Estatal, la misma protección y observancia le corresponde desempeñar al derecho administrativo.

Nuestra Carta Magna no menciona de manera expresa a la buena administración, como un derecho, principio u obligación de la Administración. Sin embargo, referencia a su contenido, lo encontramos en el artículo 76, que regula el debido proceso. Así, el numeral primero del artículo señala que corresponde a toda autoridad administrativa o judicial garantizar el cumplimiento de normas y derechos de las partes. El numeral séptimo, regula el ejercicio del derecho a la defensa que incluye el derecho a contar con el tiempo y medios adecuados para la preparación de la misma (literal b), presentar de forma verbal o escrita las razones o argumentos de los que se crea asistida y replicar los argumentos de la otra parte (literal h), motivación de resoluciones de poderes públicos (literal 1) y recurrir de las resoluciones que se emi- 
tan en procedimientos en los que se decida sobre sus derechos (literal m) (CRE, 2008). Como principio, tampoco se hace referencia expresa, no obstante, el artículo 227 de la Constitución señala que la administración pública constituye un servicio a la colectividad y está regida por los principios de eficacia, eficiencia, calidad, jerarquía, desconcentración, descentralización (CRE, 2008). Por lo anterior, podemos decir que los principios declarados en el artículo 227, conducirían al ejercicio pleno del derecho a la buena administración.

Respecto de las normas que regulan la Administración Pública, en el Estatuto del Régimen Jurídico Administrativo de la Función Ejecutiva, no existía mención expresa a la buena administración (ERJAFE, 2002). En el Código Orgánico Administrativo, sí consta referencia expresa. El artículo 31 de la norma califica a la buena administración como un derecho fundamental, esto sin perjuicio de que como se expresó anteriormente, en la Constitución de la República no se menciona verifica tal derecho. Lo que sí señala la norma que la titularidad del derecho corresponde a las personas y se concreta con la aplicación de la Constitución, instrumentos internacionales, ley y el Código Orgánico Administrativo (COA, 2017). A diferencia de lo que ocurre en otros ordenamientos jurídicos, en los que se detalla el contenido de este Derecho, como en el artículo 41 de la Carta de los Derechos Fundamentales de la Unión Europea y otros, en el país el legislador habla de la concreción del derecho por el cumplimiento de todo el sistema jurídico.

Si se revisa el Código Orgánico Administrativo, encontramos disposiciones que guardan relación directa con la Buena Administración. El artículo 32, señala que las personas tienen derecho a formular peticiones y recibir de parte de las Administraciones respuestas motivadas y de forma oportuna. El artículo 33 habla sobre el debido procedimiento administrativo. El artículo 35, dispone a los servidores públicos remover los obstáculos que retrasen o dificulten el pleno ejercicio de los derechos de las personas. El artículo 36, prohíbe a las Administraciones exigir requisitos o documentos que se hallan en el poder de la propia Administración. El artículo 37, reitera la finalidad de la Administración, interés general y garantía de goce de derechos (COA, 2017). 
Sobre principios que pueden vincularse con la buena administración, la norma dispone que su actividad deberá regirse por los siguientes principios: eficacia (art. 3), eficiencia (art. 4), calidad (art. 5), jerarquía (art. 6), desconcentración (art. 7), descentralización (art. 8), coordinación (art. 9), participación (art. 10), planificación (art. 11), transparencia (art. 12), evaluación (art. 13), juridicidad (art. 14), responsabilidad (art. 15), proporcionalidad (art. 16), buena fe (art. 17), interdicción de la arbitrariedad (art. 18), imparcialidad e independencia (art. 19), control (art. 20), ética y probidad (art. 21), seguridad jurídica y confianza legítima (art. 22), racionalidad (art. 23), protección de la intimidad (art. 24) (COA, 2017).

Por otro lado, el artículo 5 de la Ley para la Optimización y Eficiencia de Trámites Administrativos, reconoce como derechos de los administrados el obtener información completa y oportuna de los trámites administrativos, conocer el estado del trámite en cualquier momento, abstenerse de cumplir procedimientos no previstos en la norma, acceder a los registros, archivos y documentos de la Administración (Ley Orgánica para la optimización y eficiencia de trámites administrativos, 2018).

Como se puede apreciar, en el ordenamiento jurídico ecuatoriano no existe una regulación óptima sobre la buena administración como derecho, principio u obligación. En la Constitución, no existe referencia expresa y es apenas en el Código Orgánico Administrativo, donde se incluye este derecho y se le da la categoría de fundamental. A pesar de aquello, tampoco se determina en qué consiste este derecho, pues no se determina su contenido.

Otro aspecto que merece especial atención, es la categoría que se asigna al derecho a la buena administración, "fundamental". Quizá el legislador advirtió la necesidad de otorgar un estatus de protección especial al derecho, dada su importancia. Pero hay que recordar que este derecho no es reconocido expresamente en la Constitución de la República; y, que en este cuerpo normativo se establece que en el país todos los derechos gozan de igual jerarquía: "Art. 11.- El ejercicio de los derechos se regirá por los siguientes principios: 6 . Todos los principios y los derechos son inalienables, irrenunciables, 
indivisibles, interdependientes y de igual jerarquía." (CRE, 2008). Entonces, ¿̨cuál es la consecuencia práctica de que el legislador haya calificado al derecho a la buena administración, como fundamental?, si como se verifica, la Constitución otorga igual jerarquía a todos los derechos y más importante aún, no se ha determinado contenido para este derecho.

Como advertimos, nuestro ordenamiento jurídico no tiene un desarrollo adecuado respecto del derecho a la buena administración, mientras opera una reforma del Código Orgánico Administrativo (que debe ejecutarse), corresponde a la Administración, ciudadano y en suma a todos quienes sean parte en un procedimiento administrativo, efectuar un análisis doctrinario-normativo, para determinar cuáles de los derechos reconocidos en nuestro ordenamiento jurídico, pueden insertarse dentro del derecho a la buena administración.

\section{Buena Administración en el Procedimiento Administrativo}

Se ha reiterado desde el inicio del texto, que los principios y fines del Estado impregnan todas sus instituciones. Si hablamos de buena administración, se debe decir que toda la actividad de la Administración Pública deberá articularse para garantizar este derecho, entonces ¿por qué hacer referencia a la buena administración en el procedimiento administrativo?

La Administración Pública, tiene múltiples manifestaciones jurídicas, todas ellas orientadas a la consecución de fines específicos. Una de estas manifestaciones, es el procedimiento administrativo (Parejo Alfonso, 2012). Conocemos por procedimiento administrativo a la "serie, secuencia o sucesión de actos a través de la cual se expresa, ordenada y sistemáticamente, la voluntad administrativa. [...] Se puede decir, en fin, que el procedimiento administrativo constituye el cauce formal de la función administrativa" (Comadira y Escola, s.f., 2).

Este conjunto de actuaciones ejecutadas de conformidad lo dispuesto en un ordenamiento jurídico, reflejadas en expedientes 
administrativos, que preparan la declaración final o decisión de la Administración, bajo la forma de actos resolutorios (Parejo Alfonso, 2012) están orientadas a fines específicos. Parejo Alfonso (2012), los clasifica en tres: el primero, garantizar el sometimiento de las actuaciones administrativas a la ley y derecho; permitir la satisfacción de necesidades colectivas de forma ágil y rápida, por medio de la uniformización y racionalización; y, posibilitar la participación de los particulares en la toma de decisiones del poder público administrativo. Comadira por su parte, haciendo referencia a los dicho por Escola conceptúa al fin del procedimiento administrativo como "el fin de preparar la emisión de actos dirigidos a la satisfacción directa e inmediata del interés público" (Comadira y Escola, s.f., 2).

Se puede notar que los fines del procedimiento administrativo, son en suma, los fines del Estado. Por lo que no existiría problema alguno que analizar, pues luego de un breve ejercicio se ha determinado que el procedimiento administrativo, como actividad de la Administración debe sujetarse al ordenamiento normativo, orientarse a la satisfacción del interés público y desde luego al respeto y garantía del derecho a la buena administración. El problema surge cuando la aplicación de la norma, no se sujeta de forma efectiva a sus preceptos, tampoco se orienta a los fines descritos y por último, no garantiza el derecho a la buena administración.

¿Por qué reiterar en la buena administración en el procedimiento administrativo? Porque en ocasiones obviamos la importancia del procedimiento y centramos la atención de forma exclusiva en la resolución final. Este particular lo resalta García Pulles, quien señala la importancia que tiene el procedimiento administrativo en el efectivo respeto y garantía de derechos del ciudadano:

¿Por qué hablar de procedimiento administrativo, porque lejos de ser la mera "enfermería del derecho", como de forma errónea se ha pretendido llamarlo, la inobservancia de las disposiciones jurídicas en el conjunto de etapas que conducen a la emisión de actos administrativos, garantiza el efectivo respeto de derechos de los ciudadanos. (García, s.f., s.n.) 
De ahí que sea imprescindible que la Administración garantice el derecho a la buena administración en todas y cada una de las etapas del procedimiento; $y$, desde luego en todos los procedimientos que lleva a cabo. Pero más aún resulta imprescindible, que el ciudadano exija el respeto de su derecho a la buena administración en todo el procedimiento administrativo.

El artículo 41 de la Carta de Derechos Fundamentales de la Unión Europea, incluye como parte del derecho a la buena administración, el derecho de las personas a que sus asuntos sean resueltos de forma imparcial y equitativa dentro de un plazo razonable, el derecho a ser oída antes de que se emita la resolución, derecho de acceder al expediente, entre otros. Estos y otros derechos referidos por autores, tal como fue señalado, constan en el artículo 76 de la Constitución de la República, en la parte relativa al debido proceso. Si bien estos derechos, no se insertan como parte del derecho a la buena administración en nuestro ordenamiento, al estar regulados en la norma, deben ser observados y cumplidos por la Administración Pública en el procedimiento administrativo.

Entonces, si se inicia un procedimiento administrativo, la persona tiene derecho a que se emita una resolución en los plazos fijados por la norma; y, no sólo deberá cumplirse este plazo, sino también todos aquellos relativos a actuaciones procedimentales previas. De igual forma, el ciudadano tiene derecho a acceder al expediente administrativo con las excepciones previstas en el ordenamiento jurídico; además el derecho a ser escuchado de forma previa a emitir una resolución.

En el Ecuador lejos estamos a que estos derechos se cumplan de forma efectiva por la Administración Pública. Una vez iniciado un procedimiento administrativo, suelen incumplirse los plazos fijados por la norma para la ejecución o practica de etapas del procedimiento, qué decir del plazo para la emisión de la resolución final. En pocos casos, las resoluciones cumplen los parámetros requeridos por la norma para considerarlas motivadas. Acceder a un expediente administrativo resulta ser una tarea complicada, pues la Administración Pública del país, conserva aún los caracteres burocráticos de antaño. 
El ordenamiento jurídico ecuatoriano, prevé mecanismos jurídicos para exigir el cumplimiento de estos derechos, de forma individual (no como un solo derecho a la buena administración). Ante la falta de pronunciamiento de la Administración se puede activar la institución jurídica del silencio administrativo, ante la falta de motivación, la impugnación en sede administrativa o contencioso administrativa. O bien se puede iniciar un procedimiento sancionatorio contra un servidor público que incumpla sus funciones, hay que recordar que el artículo 233 de la Constitución de la República establece que ningún servidor público está exento de responsabilidades por los actos realizados en el ejercicio de sus funciones (CRE, 2008). Además se ha previsto que determinadas instituciones dentro del ámbito de su competencia, puedan vigilar el debido proceso en procedimientos administrativos, es el caso de la Defensoría del Pueblo.

Las principales razones que expone la Administración Pública por el incumplimiento de la norma, es la acumulación de trámites, ausencia de personal, entre otras. Quizá tienen la razón, como lo señala la profesora Ivanega (2020):

Una de las consecuencias de la desorganización o de la falta de recursos suele ser el exceso de trabajo como justificativo de la demora. En esto supuestos, es probable que los funcionarios judiciales o administrativos no resulten directamente responsables de tales deficiencias, sino que también sean víctimas de ellas. Pero esto no libera de responsabilidad al Estado y a los funcionarios competentes que omitieron articular mecanismos efectivos (91).

Como lo señala la doctora Ivanega, a pesar de los argumentos que pueden emitirse como justificación; y, quizá resultan ser ciertos, no se extingue la responsabilidad de la Administración Pública y de los servidores públicos, por el incumplimiento de la norma y consecuente vulneración de derechos. Más aún, si los derechos a los que hacemos referencia, son parte de aquel derecho que merece tan especial protección, por los fines a los que se orienta, el derecho a la buena administración. 
Se ha dicho que el Derecho Administrativo, junto con el Estado ha sido parte de un proceso de evolución, de dejar atrás instituciones de tinte autoritario para convertirse en una verdadera herramienta de garantía de derechos de la persona. Es momento entonces, que la Administración Pública ecuatoriana articule mecanismos para garantizar el cumplimiento efectivo del derecho a la buena administración en el procedimiento administrativo, que lejos de propender a la sanción como principal solución, se constituyan en una herramienta de prevención de vulneración de la norma. Antes de exponer las medidas que considero debería adoptar la Administración Pública ecuatoriana, es pertinente revisar aquellas propuestas desde la doctrina.

Para el profesor Damsky (2020), los procedimientos administrativos han adquirido una nueva perspectiva, cada vez son más abiertos, democráticos, participativos y están superando las antiguas características de bilateralidad y antagonismo, propias del proceso judicial. Resalta la importancia de hacer efectivo el principio de colaboración entre el ciudadano y la Administración. Por otro lado, el mismo Profesor nos habla de la necesidad de transparentar todas las actuaciones de la administración, la herramienta que nos permite hacerlo efectivo, las nuevas tecnologías de la información.

Por su parte, el profesor Juli Ponce Solé al hablar del principio de buena gobernanza, refiere que la Administración Pública debe ser ágil, rápida y consistente, sobre todo si se afecta derechos fundamentales. Debe desarrollar procedimientos internos que permitan la transparencia y disminuyan errores. (Ponce, 2014).

La doctora Ivanega (2020) por su parte, señala que al ser la buena administración una manifestación viva de la relación del ciudadano con la Administración, el modificar las estructuras administrativas, es un trabajo permanente, pues también es permanente la adecuación a demandas sociales y derechos individuales. Es decir, las actividades que decida ejecutar la Administración, deberán permanecer en el tiempo y evolucionar, de conformidad evolucionan las necesidades de la persona. 
Prats habla de políticas de buena administración, dentro de las que incluye la articulación de observatorios e instrumentos de evaluación, que cuenten con la participación, control y vigilancia del ciudadano. (Prats, 2011).

\section{Conclusiones}

Ahora bien, en este contexto en el que hemos resaltado la necesidad urgente de garantizar los derechos de la persona, en su relación con la Administración Pública, cobijados bajo la especial configuración de la Constitución de la República que coloca a la persona en el centro del actuar Estatal; y, la evolución en materia de derecho administrativo y garantía de derechos que viene operando en el mundo entero ¿qué medidas debería adoptar la Administración para garantizar el derecho a la buena Administración?

La primera de ellas, regular de forma adecuada el derecho a la buena administración en el ordenamiento jurídico. Es imprescindible que el legislador dote de contenido al derecho, siendo fiel a la categorización como fundamental (tal cual consta en el Código Orgánico Administrativo), se incorpore herramientas para que la persona lo pueda hacer efectivo. Pues de nada sirve reconocer un derecho, si no se incorpora garantías para exigir su protección.

En el ordenamiento jurídico ecuatoriano, como se señaló en este artículo, existen disposiciones que regulan y se orientan al cumplimiento de derechos que son parte de la Buena Administración, tales como motivación de actos, emisión de resoluciones en el tiempo previsto, entre otras. Sin embargo, si la norma no establece de forma precisa y clara el contenido del derecho a la buena administración (incluido principio y obligación), ante un eventual incumplimiento, la persona deberá activar una a una las herramientas jurídicas previstas en la norma, una por cada derecho vulnerado. 
Si bien con la expedición de la Ley para la Optimización y Eficiencia de Trámites Administrativos, se buscó facilitar la relación entre Administración Pública y ciudadanos, es imprescindible que la entidad rectora de la simplificación de trámites vigile su real cumplimiento.

Se tienen que establecer políticas públicas orientadas de forma exclusiva a la Buena Administración, políticas en las que se incluya: programas de capacitación permanente para los servidores públicos. Se ha insistido que la Constitución de la República, coloca a la persona como eje central del actuar estatal, en consecuencia, también el servidor público debe ser sujeto de atención. Más aún cuando, en sus manos está la observancia de la norma en un procedimiento administrativo; y, desde luego el efectivo respecto del derecho a la buena administración. El derecho administrativo, como el derecho en general, está en constante cambio, por lo tanto, los servidores públicos deben actualizarse de forma permanente.

El profesor Damsky señalaba que los procedimientos administrativos deben ser más colaborativos, es momento entonces que el ciudadano y la Administración Pública colaboren de forma efectiva. Dejemos de lado la posición de adversarios, propia de un proceso judicial y entendamos que el fin del procedimiento administrativo es diferente al fin que persigue un proceso judicial. Sólo con la activa y colaborativa participación de las partes, se puede cumplir los fines del procedimiento, del derecho administrativo, en suma del Estado.

Por otro lado, es preciso que las personas efectúen un seguimiento permanente a la actividad de la Administración Pública, la mejor forma de hacerlo, a través de asociaciones, observatorios u otro tipo de instituciones creadas con este fin específico.

Las medidas que se pueden adoptar son muchas, es momento de activar la participación; y, desde el ámbito de nuestra competencia ejecutar acciones para una debida regulación y garantía del derecho a la buena administración. Recordemos que la buena administración no es el fin, sino uno de los medios para la consecución de una finalidad superior, la garantía plena de derechos y la satisfacción del interés público. 


\section{Referencias Bibliográficas}

Ávila, R. (2009). Del Estado legal de derecho al Estado constitucional de derechos y justicia. Anuario de Derecho Constitucional Latinoamericano, (15), (775-793).

Comadira, J. y Escola, H. (s.f.). Curso de derecho administrativo. Recuperado de: https://www.academia.edu/38606845/AUTORES_JULIO_RODOLFO_COMADIRA_-HÉCTOR_JORGE_ESCOLA?email_work_car$\mathrm{d}=$ title

Damsky, I. (2019). Desde los derechos: aproximaciones a un derecho administrativo de las personas y la sociedad civil. Buenos Aires, Argentina: Ediciones Rap S.A.

Damsky, I. (2020). Revitalización del procedimiento administrativo: nueva legitimidad democrática, expansión tecnológica y rol del abogado. En D. Márquez, (Coord.). Derecho Administrativo. Ciudad de México, México: Instituto de Investigaciones Jurídicas UNAM.

García, F. (s.f.). Lecciones de Derecho Administrativo. Recuperado de: https://www.academia.edu/40299878/Garcia_Pulles_Lecciones_de_Derecho_Administrativo

Ivanega, M. (2020). Derechos fundamentales. Plazo razonable y administración pública. En D. Márquez, (Coord.). Derecho Administrativo. Ciudad de México, México: Instituto de Investigaciones Jurídicas UNAM.

Milkes, I. (2018). Buena administración y la motivación de los actos administrativos expedidos en ejercicio de facultades discrecionales. Revista digital de Derecho Administrativo, (21), (pp. 153-178). DOI: https://uexternado3.metarevistas.org/index.php/Deradm/article/view/5703

Parejo Alfonso, L. (2012). Lecciones de derecho administrativo. 5ta edición. Valencia, España: Tirant lo Blanch. Recuperado de: https://www.academia.edu/25782275/Lecciones_de_Derecho_Administrativo-Luciano_Parejo_Alfonso 
Prats, J. (2011). La lucha contra la corrupción como parte integrante del Derecho, el deber y las políticas de buena administración. Cuadernos de derecho público, (31). Recuperado de https://revistasonline.inap.es/index.php/CDP/article/view/811

Ponce, J. (2014). Ciencias sociales, Derecho Administrativo y buena gestión pública. De La lucha contra las inmunidades del poder a la batalla por un buen gobierno y una buena administración mediante un diálogo fructífero. Gestión y Análisis de Políticas Públicas, Nueva Época, (11), (pp. 2342). DOI: http://dx.doi.org/10.24965/gapp.v0i11.10176

Rodríguez-Arana, J. (2015). El Derecho Administrativo ante la crisis (El Derecho Administrativo Social). Revista de Direito ADMINISTRATIVO \& CONSTITUCIONAL, 15(60), (pp. 13-37). Recuperado de: http://www. revistaaec.com/index.php/revistaaec/article/viewFile/51/354

Rodríguez-Arana, J. (2014). La buena administración como principio y como derecho fundamental en Europa. MISIÓN JURÍDICA Revista de Derecho y Ciencias Sociales, (6), (pp. 23-56). Recuperado de: https://dialnet.unirioja.es/servlet/articulo?codigo $=5167578$

\section{Normas jurídicas}

Código Orgánico Administrativo. Asamblea Nacional del Ecuador. Registro Oficial: Suplemento 31 de 07 de julio de 2017.

Código Orgánico General del Procesos. Asamblea Nacional del Ecuador. Registro Oficial: Suplemento 506 de 22 de mayo de 2015.

Estatuto del Régimen Jurídico Administrativo de la Función Ejecutiva. Decreto Ejecutivo 2428. (27 de junio de 2017). R.O: 536 de 18 de marzo de 2002.

Ley Orgánica para la Optimización y eficiencia de trámites administrativos. Asamblea Nacional del Ecuador. Registro Oficial: Suplemento 353 de 23 de octubre de 2018. 
Constitución de la República del Ecuador. Asamblea Constituyente. Registro Oficial (2008).

Parlamento Europeo. Carta de los Derechos Fundamentales de la Unión Europea. Diario Oficial de la Unión Europea C 83/389. Recuperado de: https:// eur-lex.europa.eu/legal-content/ES/TXT/?uri=LEGISSUM\%3Al33501 